\title{
Ethnic Identity Development in Schools among First Generation Immigrants in the United States
}

\author{
Erkan Acar ${ }^{1}$, Mehmet Fatih Yigit ${ }^{1}$, Dolgun Aslan ${ }^{2}$ \\ ${ }^{1}$ Assistan Professor, Department of Sociology, Suleyman Sah University, Turkey \\ ${ }^{2}$ Dr., Ministry of National Education (MEB), Turkey \\ Correspondence: Erkan Acar, Suleyman Sah University, Istanbul, Turkey
}

Received: January 8, 2016 Accepted: January 16, $2016 \quad$ Online Published: January 21, 2016

doi:10.11114/jets.v4i4.1292 URL: http://dx.doi.org/10.11114/jets.v4i4.1292

\begin{abstract}
Today, Americans increasingly concerned about the matter of immigration in the United States. A growing number believe that immigrants are burden to the country, taking jobs and housing and creating strains on the health care system. Many Americans are also worry about the cultural impact of the expanding number of newcomers to the U.S. This paper aims to present a brief but concise discussion by reviewing literature that deals on the development of ethnic identity of first generation immigrants' students in the U.S. This is a relevant study since the influx of immigrants coming in the U.S. has made great impact on the over-all societal changes.
\end{abstract}

Keywords: first generation, immigration, immigrants, education, the United States

\section{Introduction}

Researches have been conducted to delve more into the issue of ethnic identity development among school age children. Some of these experimentations suggest that children of first-generation immigrants show that a person's ethnic identity has been formed even before adolescence. Moreover, some of these studies found out that "a child's positive sense of ethnic identity is associated with the desire to socialize with children of different racial and ethnic backgrounds" (Thomas \& Quinn, 2007). Young people do not discriminate others because of ethnicity. According to Barber (2004), psychologists and behaviorists account this attitude to children's sense of pride with their culture and ethnicity. Researches based on psychological and multicultural issues tend to match racial groups without considering the differences that occur between waves of generations of immigration. The field of sociological study, however, tackles the issue of acculturation and how society builds and influences ethnic identity among first generation immigrants. This study was designed to expand upon the limited information available regarding minority groups and attempted to add to the existing literature on the impact of being different from the dominant culture on identity and self-esteem.

\section{First Generation Immigrants}

First generation Americans (FGA) are first generations born in the United States to either one or both parents who were born and raised in other country.

\section{Immigration in the United States}

How do Americans feel about immigration? Their country, the United States of America has been called a melting pot or a salad bowl of different nationalities that are chasing after the American dream (Tichenor, 2002). Others call it a land of milk and honey. Many people around the world die over the chance of coming to America where it is thought to be the Mecca of good things in life. The U.S has become congested with non-Americans. A great population of them has been legalized yet a great fraction of the over-all population is still surviving secretly, refusing to budge from the America that they would love to be.

This topic on immigration is considered very broad. The question is how Americans feel about immigration. As Kelly (2008) explains that with the influx of immigrants, legal and illegal alike, this country has been a source of bread and butter for them while it has become a place of unemployment for the natives. Most Americans say they want a crackdown on illegal immigration. However some experts on both sides of the political divide say that may not work -for practical as well as economic reasons. As Ciment (2001) states, the government has promulgated laws to protect them and human rights violation is not an issue that the politicians want to be part of. 
As many believe that newcomers to the U.S. strengthen American society, some also believe that they threaten traditional American values that the natives have built for themselves. We can mention some of the policies that the U.S. has adopted to control migration but the answers of questions about whether those policies are implemented effectively and working without any problem are uncertain and unclear. Most of the developed countries, including the U.S., have started to implement different policies to control migration however those policies usually result in increase in irregular migration and high vulnerability of migrants on labor markets (Castles et al., 2012).

Saroop (2004) states that the liberalization of immigration policy in 1965 and subsequent legislation opened the floodgates for a new wave of immigrants. Such liberalization brought millions of people to America from parts of the world from including Asia, Africa, Europe, and South America and even in the neighboring Mexico (which claims for majority of immigrants). In 2010, the U.S. Census Bureau pegged the country's foreign-born population at 11.5 percent, not far off the historic high of 15 percent in 1910. With that statistics, it can be deduced that America has been a welcoming arm to those non-natives who seek relief and improvements in their lives. Data shows that the current phase of immigration history began in 1965 when strict quotas based on nationality were eliminated. In 1978, the U.S. government set a single annual world quota of 290,000, and this ceiling was raised again in 1990 to 700,000. Daniels (2001) points out that during the 1990s, immigrants have arrived at a pace that at times has exceeded one million new arrivals per year and have settled in all parts of the country.

When questions are raised about significant issues on immigration, the most reliable source for anything about the country's stance and laws is the Constitution. However there are only two parts of the constitution that mention about immigration. The two references in the Constitution that specifically mention "naturalization" are found in Article I, Section 8 in creating the authority of the Congress, "To establish a uniform Rule of Naturalization." Thus from a Constitutional stand point it is the responsibility of Congress to establish all laws and rules of naturalization or immigration.

\section{Challenges for First Generation Americans in Schools}

First generation American students are also considered to be those who are the first ones to attend schools in their families. This population is growing and the influx of FGAs attending primary, secondary, and even postsecondary educational institutions have somehow impacted the U.S. curriculum since there is a need to attend to this group's special needs. More importantly, FGAs in schools are facing varied challenges in their desire to finish a degree. There are conflicts in their duties, and false expectations. Moreover, they lack enough preparation, financially, culturally, socially, and psychologically. Colleges and universities across the country realize that there is indeed an increasing number of FGA students who are enrolling. According to information gathered by these educational institutions, these students come from working class families, ethnic minorities, women and adults. Especially the children of low-status immigrants are in disadvantaged situations compared to other students (Alba \& Holdaway, 2013).

Identity is defined as individual's behavioral and cognitive repertoire about who he or she is (Vignoles, Schwartz \& Luyckz, 2011). It is also claimed by some researchers that there are two dimensions of identity, that are cultural identity and personal identity (Schwartz, Zamboanga \& Weisskirch, 2008). While personal identity is about personal values and beliefs, cultural identity is related to the common beliefs, norms and ideas represented in distinct cultures. In this sense, members of immigrant groups might experience difficulties during the integration or assimilation processes. Identity development is impacted when FGA students separate themselves from the environments where the culture of their parents and American culture were likely underlined. They now live in a new environment that stresses more the American culture. Thus these students have now left their homes to be in a place where it may be necessary for them to always reaffirm their ethnicity, if they decide to. Further, many of these FGA students will move away from their homes and live near campuses. While still living with their families, their friends and community have always been there to remind them of their ethnicity. These inherent and imbibed ideas will now be challenged as they enter the college life where questions dealing with their ethnic identities will be asked.

Suarez-Orozco and Suarez-Orozco (2001) conducted a study of Asian and African FGA students that attend schools in the U.S. The study emphasized the issues of "black" identities which have prevailed in the British society in the last 20 years. The "black identities" are used to label other ethnicity compared to the "whites." The authors made very vivid and clear identifications of how the different ethnicities have fully impacted these groups accordingly. Moreover, the familial and racial ambitions of these people are the driving force behind the strong inclinations towards attending schools even with the presentation and presence of challenges that may have to be addressed, not only the pupil or student, but by the parents and community as well.

Another great obstacle that FGA students need to hurdle is surviving in two cultures (Aydin, 2014). They must make sure that their old and inborn culture is not superseded by the new culture. For some, going to school as an FGA is like a rite of passage that they need to undergo. Some parents and relatives who have never gone to U.S. schools may not be 
supportive at all because they do not know less. In fact, some of these families would obstruct an FGA's wish to further education. This is a prevalent problem for many FGAs especially if they would seem to spend more time on schoolwork and neglect some responsibilities and duties in their respective families. Such tensions almost always need to reestablish relationships with family members and friends, sometimes to the dismay of FGAs.

Another challenge for FGAs is their lack of preparation to be acquainted with other students who belong to families that are educated enough to understand the ins and outs of schooling under the U.S. educational system. Some FGA students express that in addition to the lack of preparation, they also lack the necessary knowledge of the bureaucracy of education.

\section{Addressing Challenges of First Generation Students in Schools}

Majority of schools in the country are aware of the issues that FGA students face and most of these educational institutions have formed some remedies to help alleviate the problems. Since there is continuous student recruitment and retention programs for ethnic minority students in most schools, schools formulate strategies in order to solve attrition problems that may occur among FGA students.

Specialized outreach, tutoring, and mentoring programs are just few examples of strategies that schools utilize to address these challenges. Padron (1992) reports that the Wolfson campus of Miami-Dade Community College (M-DCC) aggressively recruits students who otherwise might not attend college, including first-generation minorities, through such efforts as the Black Student Recruitment Program and the Inter American Center's outreach program in Miami's Little Havana. M-DCC's Jump Start Program targets students who have high test scores and grade point averages, but who have expressed little interest in postsecondary education.

Min (1997) states that other strategies to help FGA students include the bridge programs that provide networks between the experiences that FGA students had in the primary, secondary, and college levels. This program is found to be successful since it fills the gaps that FGA students have in their lack of preparation in college. Some colleges would even bring FGA high school students to their campuses to visit and observe actual college life. Some international elementary and high schools have special remedial language classes for those who are recent immigrants. Still, some schools offer summer classes for these FGA students to enhance what they already know, focusing on study skills and communication.

Efforts done by schools to assist FGA students succeed are continuous. Many of FGAs expressed their gratitude over the help extended to them, especially academically and socially. On the other hand, ample evidence shows that parental involvement is significantly important on students' academic and disciplinary success (Cheadle, 2008; Leonard, 2013; Sad, 2012). Parental involvement includes but not limited to (1) establishing home environments to support children as students with tutoring and mentoring, (2) communicating with school for the programs and the students' progress, (3) decision making by developing parent leaders and representatives on school teams and councils, and (4) collaborating with community by identifying services resources and expectations to strengthen school programs and students' learning (Hill \& Tyson, 2009). Such parental involvement becomes crucial when it comes to immigrant students' academic and disciplinary success including the FGA students. With respect to the importance of parental involvement many programs developed, offered and applied by the educators and policy makers in the U.S. especially for the FGA students and for their parents. For instance, "Lee Y Seras" program is specifically designed for Latino parents and their children between the age of zero and eight. Literacy workshops for parents as well as workshops for teachers and care providers serving the community, both with emphasis on Latin American culture were the core elements that shaped the program. Sponsored by sponsored by the National Council of La Raza, "Lee Y Seras" program showed parents how to construct literacy activities out of everyday life (Goldenberg \& Light, 2009). "AVANCE" was another program designed for low-income Latino parents of children age three to eight. Early children education and parenting education in home and site are offered to Latino parents who have the least parental involvement in the U.S. education system. AVANCE program showed that increased parent knowledge, skills, efficacy, and use of services as well as improvements in home learning environment significantly increased among the parents of Latino origin FGAs (Bridges et al. 2009).

\section{White and Black Cultures: Achievement by First Generation Immigrant Students}

According to Karoly and Gabriella (2011), poor school achievements by most First Generation Americans can be blamed on the oppositions that they get about schooling. Consequently, these immigrants who are somehow forced by circumstances to undergo education experience hardships and face challenges in keeping their ethnic identities and at the same time ensuring themselves of academic success. For them, the latter is not as important since succeeding academically is more of a white behavior than it is to minorities. For many of these ethnic individuals who strive for academic success they would have to sacrifice their ethnic identities. Fordham and Ogbu (1986) enumerate some school behaviors that are labeled as "white behaviors" including participating in class discussions, carrying books to class, 
asking teachers for help in the presence of classmates, working hard to excel in school, getting good grades, spending most of the time in libraries, and being punctual in classes. Since these aforementioned behaviors are identified with whites, those who belong to the minority groups are hesitant to do them because they believe that it is not fitting for them. They deem that they could do the opposite behaviors of what whites are known to do. Therefore, if a minority would perform these "white behaviors," it would mean giving up their ethnic identities. Furthermore, those who want to succeed academically would have to reject their culture in favor of the white culture. Still, those minority students who act like "white" must be prepared for opposition from peers who think that they are traitors to the culture and race.

Many of these black minorities who are brilliant and intelligent sometimes result to playing down their achievements by pretending to be dull to escape persecutions from peers. In other words, they prefer isolation and socialize with their black schools friends. They prefer academically and disciplinary resembling each other rather than individually excelling in school since the image of being excellence is an act of "whites" for those students. Yet some also assume neutrality and do not side with either colors.

\section{Conclusion}

Challenges that first generation American students in U.S. schools are still existing and prevalent today. Educators and policy makers in the U.S. need vision of inclusive schools where all students including FGA students could flourish, feel welcome and have the sense of belonging (Read, et al, 2015). Furthermore, studies show that communication is one area that has to be developed and enhanced for those FGA students who wish to survive in the diversity of their environment. Competition is also inherent in schools as academic excellence is a prize that many of these minorities want to earn. Yet, it is important to treat one of the major causes of their inability or slow progress. Language barrier is a glaring fact that needs to be addressed. Two possible remedies are presented by the school system: bilingual education and the administration of ESL classes.

Bilingual education is not a very new type of education since it dates back to the early 60's. This is a type of education where information and lessons uses two or more languages (Kaya, 2015). So far, there are known positive and negative effects of bilingual education. Hernandez-Sheets and Hollins (1999) writes that educators and other professionals who study the effectiveness of such kind of school system have found out many factors that propagate bilingual education. Non-American students should learn English at the same time in the native tongue that they are born with. It would make learning easier and they will not forget the language that is part of their culture. Bilingual education provides students will an effective tool later on in life. As globalization is a glaring realization, it is but necessary to be equipped with the necessary skills that bilingual education can give. Students become adept in English as well as another language or languages (Inceli, 2015).

According to Banks (2005), they would be able to survive in a world where other languages are being used as well. Immigrant students who are immersed in the mainstream English classes get lost in the instruction, thus failures are inevitable. Kids who get special classes using their own tongue are slowly blending in to the mainstream. Bilingual education is here to help disadvantaged immigrant children (Faltis, 2014; Medina, 2003). Its existence will not help their families economically nor will it provide good jobs for their parents (Holcomb-McCoy, 2005). The socio-economics status of the community will not benefit from bilingual education as well because it is focused on a target group: non-native English children (Aydin \& Ozfidan, 2014). This will change their lives, equip them will the appropriate tool, aid them to survive in a confusing world, and prepare them for the years ahead when they have to fend for themselves. The "sink and swim" theory of learning a language, although effective in some sense, can be innovated. Why make children's lives difficult when there is an alternative by affecting bilingual education into the school system (Banks \& Banks, 204).

English as a Second Language (ESL) is a pertinent topic in the educational system. Teaching English to non-native English speakers entails proper training and qualifications. On the other hand, learning English as a second language needs enough time and the appropriate strategies. The role of English as a Second Language as part of the school curriculum and specially designed for first-generation immigrants and their children is significant.

According to a study made by the National Center on Immigrant Integration Policy, "learning to speak, read, and write in the English language is the most important integration challenge that faces more than one million immigrants who arrive in the U.S. each year (Choi-Milling, 1998). These immigrants need to have English language skills in order to function effectively in three core roles - as leaders and caretakers of their families, as members of their communities, and as workers at their workplace. These roles loosely correspond to the types of ESL and literacy programs that have been developed over the past 25 years, and which now comprise the "potluck" array of instruction programs offered in adult education classrooms around the country today." 


\section{References}

Alba, R., \& Holdaway, J. (2013). The children of immigrants at school: A comparative look at integration in the United States and Western Europe. New York, NY: New York University Press.

Aydin, H. (2014). A Comparative Study between the United States and Turkey on Teachers' Lesson Planning Effort. Review of Research and Social Intervention, 46(1), 99-117.

Aydin, H., \& Ozfidan, B. (2014). Perceptions on Mother Tongue (Kurdish) based multicultural and bilingual education in Turkey. Multicultural Education Review, 6(1), 21-48. http://dx.doi.org/10.14328/MER.2014.03.31.21

Banks, C. A. M. (2005). Improving multicultural education: Lessons from the intergroup education movement. New York: Teachers College Press.

Banks, J. A., \& Banks, C. A. M. (2004). Handbook of research on multicultural education. San Francisco, CA: Jossey-Bass.

Barber, S. E. (2004). Immigration and public education in America. Project (B.S.) James Madison University, 2004.

Bridges, M., Shana, C., Bruce, F., \& Veronica, V. (2009). Evaluation of Abriendo Puertas. Los Angeles: Families in Schools. http://www.familiesinschools.org/site/images/stories/fruit/ laccpcexecsumforweb.pdf.

Castles, S., Arias, C. M., Kim, C., \& Ozkul, D. (2012). Irregular migration: Causes, patterns and strategies in Omelaniuk, I. National Institute for Migration Mexico (INAMI) (edt) Reflections on Migration and Development, Berlin and Geneva: Springer and International Organization for Migration.

Cheadle, J. E. (2008). Educational Investment, Family Context, and Children's Math and Reading Growth from Kindergarten through Third Grade. Sociology of Education, 81, 1-31. http://dx.doi.org/10.1177/003804070808100101

Choi-Milling, B. (1998). A task-based curriculum for ESL Chinese students. Thesis (M.A.)-California State University, Dominguez Hills, 1998.

Ciment, J. (2001). Encyclopedia of American Immigration. Armonk, N.Y.: M.E. Sharpe.

Daniels, R. (2001). American immigration: a student companion. Oxford student companions to American history. Oxford [England]: Oxford University Press.

Faltis, C. (2014). Toward a Race Radical Vision of Bilingual Education for Kurdish Users in Turkey: A Commentary. Journal of Ethnic and Cultural Studies, 1(1), 1-5.

Fordham, S. \& Ogbu, J. U. (1986). Black Students', School Success: Coping With the Burden of 'Acting White'. Urban Review, 18(3), 176-206. http://dx.doi.org/10.1007/BF01112192

Goldenberg, L., \& Light, D. (2009). Lee y Seras: Evaluation report. New York: Education Development Center, Inc.

Hernandez-Sheets, R., \& Hollins, E. R. (1999). Racial and ethnic identity in school practices aspects of human development. Mahwah, N.J.: L. Erlbaum Associates.

Hill, N. E., \& Tyson, D. F. (2009). Parental Involvement in Middle School: A Meta-Analytic Assessment of the Strategies that Promote Achievement. Developmental Psychology, 45, 740-763. http://dx.doi.org/10.1037/a0015362

Holcomb-McCoy, C. (2005). Ethnic Identity Development in Early Adolescence: Implications and Recommendations for Middle School Counselors. Professional School Counseling, 9(2), 120-127. http://dx.doi.org/10.5330/prsc.9.2.21q8m2724r545414

Inceli, O. (2015). The Perceptions of English Teachers to the SIOP® Model and Its Impact on Limited English Proficiency. Journal of Ethnic and Cultural Studies, 2(1), 15-28.

Karoly, L. A., \& Gonzalez, G. C. (2011). Early Care and Education for Children in Immigrant Families. Future of Children, 21(1), 71-101. http://dx.doi.org/10.1353/foc.2011.0005

Kaya, Y. (2015). Teachers' Perceptions on Culturally Responsiveness in Education. Journal of Ethnic and Cultural Studies, 2(2), 33-46.

Kelly, T. K. (2008). Immigration to the United States, 1789-1930. Journal of American History-Bloomington, 94(4), 13-32.

Leonard, J. (2013). Maximizing College Readiness for All through Parental Support. School Community Journal, 23(1), 183-202. 
Marcello Suarez-Orozco, Harvard University Press, 2002, 206 pp. American Journal of Psychoanalysis, 64(2), 219-222. http://dx.doi.org/10.1023/B:TAJP.0000027372.77917.93

Medina, L. M. (2003). Bilingual education. San Diego (California): Greenhaven Press.

Min, Z. (1997). Growing Up American: The Challenge Confronting Immigrant Children and Children of Immigrants. Annual Review of Sociology, 23, 63-95. http://dx.doi.org/10.2307/2952544

Padron, E. J. (1992). The Challenge of First Generation College Students: A Miami-Dade Perspective. New Directions for Community Colleges, 80, 71-80. http://dx.doi.org/10.1002/cc.36819928009

Read, K., Aldridge, J., Ala'i, K., Fraser, B., \& Fozdar, F. (2015). Creating a climate in which students can flourish: A whole school intercultural approach. International Journal of Whole Schooling, 11(2), 29-44.

Sad, S. N. (2012). Investigation of Parental Involvement Tasks as Predictors of Primary Students' Turkish, Math, and Science \& Technology Achievement. Eurasian Journal of Educational Research, 48, 135-154.

Saroop, S. (2004). Book Review: Children of Immigration, by Carola Suarez-Orozco and

Schwartz, S. J., Zamboanga, B. L., \& Weisskirch, R. S. (2008). Broadening the Study of the Self: Integrating the Study of Personal Identity and Cultural Identity. Social and Personality Psychology Compass, 2, 635-651. http://dx.doi.org/10.1111/j.1751-9004.2008.00163.x

Suarez-Orozco, C., \& Suarez-Orozco, M. M. (2001). Children of immigration. The developing child. Cambridge, MA: Harvard University Press.

Thomas, L., \& Quinn, J. (2007). First generation entry into higher education: an international study. Maidenhead: Society for Research into Higher Education.

Tichenor, D. J. (2002). Dividing lines the politics of immigration control in America. Princeton studies in American politics. Princeton, N.J.: Princeton University Press.

Vignoles, V. L., Schwartz, S. J., \& Luyckz, K. (2011). Introduction: Toward an integrative view of identity. Handbook of identity theory and research. (pp. 1-27). New York, NY: Springer. http://dx.doi.org/10.1007/978-1-4419-7988-9_1

\section{$(\mathrm{Cc}) \mathrm{BY}$}

This work is licensed under a Creative Commons Attribution 3.0 License. 